\title{
Correlates of overall and central obesity in adults from seven European countries: findings from the Food4Me Study
}

Article

Accepted Version

Celis-Morales, C., Livingstone, K. M., Affleck, A., NavasCarretero, S., San-Cristobal, R., Martinez, J. A., Marsaux, C. F. M., Saris, W. H. M., O'Donovan, C. B., Forster, H., Woolhead, C., Gibney, E. R., Walsh, M. C., Brennan, L., Gibney, M., Moschonis, G., Lambrinou, C.-P., Mavrogianni, C., Manios, Y., Macready, A. L., Fallaize, R., Lovegrove, J. A., Kolossa, S., Daniel, H., Traczyk, I., Drevon, C. A. and Mathers, J. C. (2018) Correlates of overall and central obesity in adults from seven European countries: findings from the Food4Me Study. European Journal of Clinical Nutrition, 72 (2). pp. 207219. ISSN 0954-3007 doi: https://doi.org/10.1038/s41430-0170004-y Available at https://centaur.reading.ac.uk/74604/

It is advisable to refer to the publisher's version if you intend to cite from the work. See Guidance on citing.

To link to this article DOI: http://dx.doi.org/10.1038/s41430-017-0004-y Publisher: Nature Publishing Group 
including copyright law. Copyright and IPR is retained by the creators or other copyright holders. Terms and conditions for use of this material are defined in the End User Agreement.

\section{www.reading.ac.uk/centaur}

\section{CentAUR}

Central Archive at the University of Reading

Reading's research outputs online 
1 Correlates of overall and central obesity in adults from seven European countries: Findings from the Food4Me

2 Study

3 Running title: Correlates of obesity

4 Authors

5 Carlos Celis-Morales ${ }^{1,2^{*}}$, Katherine M Livingstone ${ }^{1^{*}}$, Alexander Affleck $^{2}$, Santiago Navas-Carretero ${ }^{3}$, Rodrigo San-

6 Cristobal $^{3}$, J Alfredo Martinez ${ }^{3}$, Cyril F M Marsaux ${ }^{4}$, Wim H M Saris ${ }^{4}$, Clare B O’Donovan ${ }^{5}$, Hannah Forster ${ }^{5}$, Clara $^{\prime}$

7 Woolhead $^{5}$, Eileen R Gibney ${ }^{5}$, Marianne C Walsh ${ }^{5}$, Lorraine Brennan ${ }^{5}$, Mike Gibney ${ }^{5}$, George Moschonis ${ }^{6}$, Christina-

8 Paulina Lambrinou $^{6}$, Christina Mavrogianni ${ }^{6}, Y$ annis Manios ${ }^{6}$, Anna L Macready ${ }^{7}$, Rosalind Fallaize ${ }^{7}$, Julie A

9 Lovegrove ${ }^{7}$, Silvia Kolossa ${ }^{8}$, Hannelore Daniel ${ }^{8}$, Iwona Traczyk ${ }^{9}$, Christian A Drevon ${ }^{10}$, John C Mathers ${ }^{1}$, on behalf of 10 the Food4Me Study.

\section{Author affiliations}

${ }^{1}$ Human Nutrition Research Centre, Institute of Cellular Medicine, Newcastle University, Newcastle Upon Tyne, UK

${ }^{2}$ BHF Glasgow Cardiovascular Research Centre, Institute of Cardiovascular and Medical Sciences, University of

${ }^{3}$ Department of Nutrition, Food Science and Physiology, University of Navarra, Pamplona, Spain.

${ }^{4}$ Department of Human Biology, NUTRIM, School for Nutrition and Translational Research in Metabolism, Maastricht

${ }^{5}$ UCD Institute of Food and Health, UCD School of Agriculture and Food Science, University College Dublin, Belfield,

Dublin 4, Republic of Ireland

${ }^{6}$ Department of Nutrition and Dietetics, Harokopio University, Athens, Greece.

${ }^{7}$ Hugh Sinclair Unit of Human Nutrition and Institute for Cardiovascular and Metabolic Research, University of

${ }^{8}$ ZIEL Research Center of Nutrition and Food Sciences, Biochemistry Unit, Technische Universität München,

${ }^{9}$ Human Nutrition Department, Faculty of Health Sciences, Medical University of Warsaw, Warsaw, Poland.

* These authors contributed equally to this work 
31 Professor John C. Mathers

32 Human Nutrition Research Centre

33 Institute of Cellular Medicine

$34 \quad$ Newcastle University

35 Campus for Ageing and Vitality

36 Newcastle upon Tyne

$37 \quad$ NE4 5PL

$38 \quad$ UK

39 john.mathers@newcastle.ac.uk

40 Tel: +44 (0) 1912081133

41 Fax: +44 (0) 1912081101 
Background/Objectives: To identify predictors of obesity in adults and investigate to what extent these predictors are independent of other major confounding factors.

Subjects/Methods: Data collected at baseline from 1,441 participants from the Food4Me study conducted in seven European countries were included in this study. A food frequency questionnaire was used to measure dietary intake; Accelerometers were used to assess physical activity levels (PA), whereas participants self-reported their body weight, height and waist circumference via the internet.

Results: The main factors associated $(p<0.05)$ with higher BMI per 1-SD increase in the exposure were age $(\beta: 1.11$ $\left.\mathrm{kg} / \mathrm{m}^{2}\right)$, and intakes of processed meat $\left(\beta: 1.04 \mathrm{~kg} / \mathrm{m}^{2}\right)$, red meat $\left(\beta: 1.02 \mathrm{~kg} / \mathrm{m}^{2}\right)$, saturated fat $\left(\beta: 0.84 \mathrm{~kg} / \mathrm{m}^{2}\right)$, monounsaturated fat $\left(\beta: 0.80 \mathrm{~kg} / \mathrm{m}^{2}\right)$, protein $\left(\beta: 0.74 \mathrm{~kg} / \mathrm{m}^{2}\right)$, total energy intake $\left(\beta: 0.50 \mathrm{~kg} / \mathrm{m}^{2}\right)$, olive oil $(\beta: 0.36$ $\left.\mathrm{kg} / \mathrm{m}^{2}\right)$, sugar sweetened carbonated drinks $\left(\beta: 0.33 \mathrm{~kg} / \mathrm{m}^{2}\right)$ and sedentary time $\left(\beta: 0.73 \mathrm{~kg} / \mathrm{m}^{2}\right)$. In contrast, the main factors associated with lower BMI per 1-SD increase in the exposure were PA $\left(\beta:-1.36 \mathrm{~kg} / \mathrm{m}^{2}\right)$, and intakes of wholegrains $\left(\beta:-1.05 \mathrm{~kg} / \mathrm{m}^{2}\right)$, fibre $\left(\beta:-1.02 \mathrm{~kg} / \mathrm{m}^{2}\right)$, fruits and vegetables $\left(\beta:-0.52 \mathrm{~kg} / \mathrm{m}^{2}\right)$, nuts $\left(\beta:-0.52 \mathrm{~kg} / \mathrm{m}^{2}\right)$, polyunsaturated fat $\left(\beta:-0.50 \mathrm{~kg} / \mathrm{m}^{2}\right)$, Healthy Eating Index $\left(\beta:-0.42 \mathrm{~kg} / \mathrm{m}^{2}\right)$, Mediterranean diet score $\left(\beta:-0.40 \mathrm{~kg} / \mathrm{m}^{2}\right)$, oily fish $\left(\beta:-0.31 \mathrm{~kg} / \mathrm{m}^{2}\right)$, dairy $\left(\beta:-0.31 \mathrm{~kg} / \mathrm{m}^{2}\right)$ and fruit juice $\left(\beta:-0.25 \mathrm{~kg} / \mathrm{m}^{2}\right)$.

Conclusions: These findings are important for public health and suggest that, promotion of increased PA, reduced sedentary behaviours and improving the overall quality of dietary patterns are important strategies for addressing the existing obesity epidemic and associated disease burden.

Key Words - Obesity; physical activity, diet, healthy eating index, Mediterranean diet.

Trial registration - Clinicaltrials.gov NCT01530139 


\section{INTRODUCTION}

Excess adiposity, represented by high body-mass index (BMI) and waist circumference (WC), is a known risk factor for cardiovascular diseases, some cancers, and premature mortality. ${ }^{1} \mathrm{~A}$ recent study conducted in more than 19.2 million adult worldwide provided evidence that obesity is a growing pandemic, with the prevalence of obesity having increased from $3.2 \%$ in 1975 to $10.8 \%$ in 2014 in men, and from $6.4 \%$ to $14.9 \%$ in women. ${ }^{2}$ Concerns regarding the health and economic burden of growing obesity rates have led to adiposity being included among the global non-

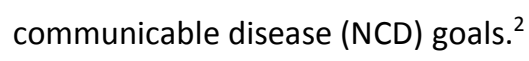

Changes in lifestyle related to energy balance, including insufficient levels of physical activity (PA) and higher energy intake have been proposed as the main driving force behind the rise in obesity over recent decades., ${ }^{3,4}$ The processes of modernization, urbanization and globalisation of eating behaviours have affected dietary intake and PA patterns and have subsequently contributed to the development of obesity. ${ }^{5}$ Thus, a detailed understanding of the behavioural factors associated with obesity is essential for the design and implementation of effective public health interventions aimed to prevent or manage obesity.

The present study uses baseline data from the Food4Me study, a pan-European randomized controlled trial, designed to investigate the effect of personalized nutrition (PN) advice on changes in diet and PA after a 6-month intervention. ${ }^{6}$, ${ }^{7}$ Our study aims to identify predictors of obesity in European adults and to investigate to what extent these predictors are independent of other major confounding factors.

\section{MATERIALS AND METHODS}

\section{Study population}

The Food4Me Proof of Principle (PoP) study was a 6-month, internet-based, randomised controlled trial (RCT) conducted across seven countries in Europe (www.food4me.org). ${ }^{6,7}$ Out of 5,662 individuals who were interest in this trial (mean age 40 (SD: 12.7); range 15-87 years) between August 2012 and August 2013, the first 1,441 volunteers meeting the inclusion criteria and with available data for the analysis were included in the present study. Participants were recruited from the following recruitment sites: Maastricht University (The Netherlands), University College Dublin (Ireland), University of Navarra (Spain), University of Reading (United Kingdom, UK), Harokopio University 
(Greece), Technical University of Munich (Germany) and National Food and Nutrition Institute (Poland), were included in the study. Participants aged $<18$ years, pregnant or lactating, with limited access to the Internet, follow a prescribed diet for any reason were excluded from the study. The Research Ethics Committees at each Research Centre granted ethics approval for the study.

\section{Study measures}

Participants agreed to self-report their measures via the internet. To ensure that procedures were comparable in all recruiting centres, standardised operating procedures were arranged for all measurements. ${ }^{6,7}$

An online screening questionnaire collected detailed self-reported (SR) information on socio-demographic, dietary, food choices, anthropometric and health-related data. At baseline, anthropometric measures were self-measured and self-reported via the internet. Participants were instructed to measure body weight after an overnight fast, barefoot and wearing light clothing using a commercial or home scale, and to measure height using a measuring tape provided by Food4Me study. ${ }^{6,7}$ Waist circumference (WC) was measured at the mid-point between the lower rib and the iliac crest. Central obesity was set as WC $>102 \mathrm{~cm}$ and $>88 \mathrm{~cm}$ for men and women, respectively. BMI was calculated from body weight divided by height square. The WHO criteria for BMI was used to define nutritional status (underweight $<18.5$, normal weight $\geq 18.5$ to $\leq 24.9$, overweight $\geq 25.0$ to $\leq 29.9$ and obese $\left.\geq 30.0 \mathrm{~kg} / \mathrm{m}^{2}\right) .{ }^{8}$ These self-reported measurements were repeated in a random sub-sample of 140 participants who were invited to participate in a validation study, these results are described in supplementary methods and elsewhere. ${ }^{9}$

Occupational activities were grouped according to the European classifications a) professional and managerial, b) intermediate, c) routine and manual, d) service and sales workers, e) elementary occupations, f) students and g) retired. ${ }^{10}$

Objective physical activity levels (PAL= total energy expenditure / basal metabolic rate) and time spent in sedentaryrelated behaviours (min/day) were assessed using triaxial accelerometers (TracmorD, Philips Consumer Lifestyle, The Netherlands). Participants were instructed to wear the accelerometer every day during waking hours, apart from when taking a shower, for the entire duration of the study. Intensities of PA were derived using thresholds for activity energy expenditure for sedentary behaviours (corresponding to $<1.5 \mathrm{METs}$ ), light ( 1.5 to $<3 \mathrm{METs}$ ), moderate ( 3 to $<6 \mathrm{METs}$ ), vigorous ( $\geq 6$ METs) or moderate-equivalent intensity PA. ${ }^{11}$ Moderate-equivalent PA was derived using the equation [moderate PA + (vigorous PA $\times 2$ )]. Individuals who accumulated $\geq 150$ minutes of moderate-equivalent PA a week 
115

were classified as physically active. ${ }^{11}$ Additional information on physical activity measure is provided in supplementary material.

At baseline, participants completed an online Food frequency questionnaire (FFQ) to estimate usual dietary intake during the last month. This FFQ, was developed for the Food4Me Study ${ }^{12,13}$ and included 157 food items consumed frequently in each of the seven recruitment countries. The reproducibility and validity of the FFQ was assessed and these details are reported in our Supplementary Methods and elsewhere. ${ }^{14,15}$ Intakes of foods and nutrients were computed in real time using a food composition database based on McCance \& Widdowson's “The composition of foods" ${ }^{16}$ Intakes were assessed using a standardized set of recommendations ${ }^{17}$ for foods and food groups including fruit and vegetable, wholegrain products, dairy products, oily fish, red meat, processed meat, fats and spreads, fruit juice, sugar sweetened carbonated drinks, sweets and pastries, nut, vegetable oil and olive oil. ${ }^{17}$

Furthermore, two healthy eating scores were derived to measure the overall diet quality. The first one, adherence to the Mediterranean diet (MD) was estimated based on the PREDIMED 14-point criteria ${ }^{18}$ (Supplemental Table 1). FFQs at baseline were used to derive each of the following criteria: higher intake of olive oil than other culinary fat, higher intake of white meat than red meat, high intake of fruit (including natural fruit juice), vegetables, olive oil, legumes, nuts, fish, wine and tomato-based sauces and limited intakes of red and processed meats, fats and spreads, soft drinks and commercial bakery goods, sweets and pastries. ${ }^{18}$ Participants scored 1 point for each of the 14 criterion they met and 0 for each they did not meet; points were summed to create an overall MD score, ranging from $0-14 .^{18}$

The second diet quality score was derived using the Healthy Eating Index (HEI), which was updated and validated to reflect the 2010 Dietary Guidelines for Americans and the accompanying USDA Food Patterns. ${ }^{19}$ The HEI-2010 includes 12 food groups, 9 of which assessed adequacy of the diet, including 1) total fruit; 2) whole fruit; 3) total vegetables; 4) greens and beans; 5) whole grains; 6) dairy; 7) total protein foods; 8) seafood and plant proteins; and 9) fatty acids. The remaining three factors, refined grains, sodium, and empty calories (i.e., energy from solid fats, alcohol, and added sugars), assess dietary components that should be consumed in moderation. Higher scores reflected better diet quality. Scores for each of the 12 items are summed to produce a total score with a maximum value of $100 .^{19}$

\section{Statistical analysis}


Multivariate Linear Regression analyses were performed to test for associations between the outcomes (BMI and WC) and the exposures of interest, including age, physical activity and dietary intake. For comparison purposes, all continuous exposures were standardised and presented as standard deviation (SD) units. The odds for overweight and obesity $\left(\mathrm{BMI} \geq 25.0 \mathrm{~kg} / \mathrm{m}^{2}\right.$ ) and central obesity (WC $>88$ and $>102 \mathrm{~cm}$ for women and men, respectively) were estimated by socio-demographics, PA and dietary intake variables. Tertiles for each of these continuous variables were derived using the standardised variables.

Analyses were adjusted incrementally. Model 1 was adjusted for age, sex, country and occupation, whereas Model 2 was additionally adjusted for total time spent in sedentary behaviours and total PA for dietary outcomes, and monitor wearing time and total energy intake for physical activity outcomes. Total energy intake was included in model 2 for PA exposures to elucidate whether the association between PA and our outcomes of interest goes beyond an effect of total energy intake. Data were analysed using Stata (version 14; StataCorp. TX, USA). Results were deemed significant at $P$-value $<0.05$.

\section{RESULTS}

\section{Cohort characteristics}

Of the 1,607 participants randomised into the Food4Me trial, data at baseline on BMI were available for 1,441 participants ( $58 \%$ were women and $97 \%$ were Caucasian), characteristics of the drop outs have been described elsewhere ${ }^{20}$. As summarised in Table 1, the mean age was 40.1 years (range: 18 to 79 ), $30 \%$ of individuals were overweight and $16 \%$ were obese. Although $47 \%$ of participants where classified as physically active, $28 \%$ of participants recorded less than 1 minute of vigorous intensity PA daily. Dietary intakes of nutrients and food groups and diet quality scores by BMI and WC categories are described in Tables 1 and Table S2.

\section{Association of BMI and WC with socio-demographic, dietary and physical activity factors}

As presented in Table 2, the main factors associated with higher BMI per 1-SD increase in the exposure or independent variable were age $\left(\beta: 1.11 \mathrm{~kg} / \mathrm{m}^{2}\right)$, and intakes of processed meat $\left(\beta: 1.04 \mathrm{~kg} / \mathrm{m}^{2}\right)$, red meat $(\beta: 1.02$ $\left.\mathrm{kg} / \mathrm{m}^{2}\right)$, saturated fat $\left(\beta: 0.84 \mathrm{~kg} / \mathrm{m}^{2}\right)$, monounsaturated fat $\left(\beta: 0.80 \mathrm{~kg} / \mathrm{m}^{2}\right)$, protein $\left(\beta: 0.74 \mathrm{~kg} / \mathrm{m}^{2}\right)$, total energy $\left(\beta: 0.50 \mathrm{~kg} / \mathrm{m}^{2}\right)$, olive oil $\left(\beta: 0.36 \mathrm{~kg} / \mathrm{m}^{2}\right)$, sugar sweetened carbonated drinks $\left(\beta: 0.33 \mathrm{~kg} / \mathrm{m}^{2}\right)$ and time spent sedentary 
$\left(\beta: 0.73 \mathrm{~kg} / \mathrm{m}^{2}\right)$. In addition, total sugars intake was negatively associated with $W C\left(\beta:-1.03 \mathrm{~kg} / \mathrm{m}^{2}\right.$ per $1-\mathrm{SD}$ increase in total sugars intake).

The main factors associated with BMI per 1-SD increase in the exposure were moderate-equivalent PA ( $\beta$ :-1.36 $\left.\mathrm{kg} / \mathrm{m}^{2}\right)$, light PA $\left(\beta:-0.77 \mathrm{~kg} / \mathrm{m}^{2}\right)$, and intakes of wholegrains $\left(\beta:-1.05 \mathrm{~kg} / \mathrm{m}^{2}\right)$, fibre $\left(\beta:-1.02 \mathrm{~kg} / \mathrm{m}^{2}\right)$, fruits and vegetables $\left(\beta:-0.52 \mathrm{~kg} / \mathrm{m}^{2}\right)$, nuts $\left(\beta:-0.52 \mathrm{~kg} / \mathrm{m}^{2}\right)$, polyunsaturated fat $\left(\beta:-0.50 \mathrm{~kg} / \mathrm{m}^{2}\right), \mathrm{HEI}\left(\beta:-0.42 \mathrm{~kg} / \mathrm{m}^{2}\right), \mathrm{MD} \mathrm{score}$ $\left(\beta:-0.40 \mathrm{~kg} / \mathrm{m}^{2}\right)$, oily fish $\left(\beta:-0.31 \mathrm{~kg} / \mathrm{m}^{2}\right)$, dairy products $\left(\beta:-0.31 \mathrm{~kg} / \mathrm{m}^{2}\right)$ and fruit juice $\left(\beta:-0.25 \mathrm{~kg} / \mathrm{m}^{2}\right)$. As summarised in Table 2, these associations were independent of sex, occupation and country (Model 1), as well as total PA, sedentary behaviours, total energy intake and total accelerometer wear time. Similar results were found for WC (Table 3), although the magnitudes of the associations per 1-SD increase in the exposure were stronger than for BMI (Table 2).

\section{Correlates of overall and central obesity}

Figure 1 describes the odds ratio of being overweight or obese $\left(B M I \geq 25.0 \mathrm{~kg} / \mathrm{m}^{2}\right)$ and centrally obese $(W C>88 \mathrm{~cm}$ for females and $>102 \mathrm{~cm}$ for males). Participants in the highest tertile for moderate-equivalent PA (highly active) were $80 \%$ less likely to have a $\mathrm{BMI} \geq 25.0 \mathrm{~kg} / \mathrm{m}^{2}$ compared with those in the lowest tertile (less active). Similarly, younger participants were $71 \%$ less likely to have $\mathrm{BMI} \geq 25.0 \mathrm{~kg} / \mathrm{m}^{2}$ than older participants (higher tertile). Those participants who were female, students, from Germany and the Netherlands, and those in the lowest tertile for sedentary behaviour, light intensity PA or total PA, were less likely to be overweight or obese compared with their reference group (Figure 1). Similar results, but with stronger effect sizes, were observed when central obesity was used as the outcome (Figure 1).

When nutrients intake were used as main exposures (Figure 2), participants in the lowest tertile for monounsaturated, saturated and total fats, salt and total energy intake were less likely to have a BMI $\geq 25.0 \mathrm{~kg} / \mathrm{m}^{2}$ than their counterparts in the higher tertile. In contrast, individuals in the lowest tertile for polyunsaturated fat and vegetable oil intake were more likely to have a BMI $\geq 25.0 \mathrm{~kg} / \mathrm{m}^{2}$ compared with participants in the highest tertile (Figure 2 and Table S3). Similarly, central obesity was less likely among those with lowest intakes of protein, carbohydrates, monounsaturated fat, and salt. However, individuals in the lower tertile for sugar intake were more 
197

198

199

200

201

202

203

204

205

206

207

208

209

210

211

212

213

214

215

216

217

likely to have central obesity (Figure 2). The odds of having BMI $\geq 25.0 \mathrm{~kg} / \mathrm{m}^{2}$ or central obesity by food group are presented in Figure 3.

\section{Discussion}

Our main findings are the associations between intakes of nutrients and of healthy and unhealthy foods as well as healthy eating score with markers of overall and central obesity in adults from seven European countries. Our study found that the strongest positive correlates with adiposity were age and reported intakes of processed meat, red meat or saturated fat (effect size ranging from 1.11 to $0.84 \mathrm{~kg} / \mathrm{m}^{2}$ per 1-SD increase in the exposure), whereas the strongest negative correlates of adiposity were moderate-equivalent PA, and reported intakes of wholegrain or dietary fibre intake, with effect sizes ranging from -1.36 to $-1.02 \mathrm{~kg} / \mathrm{m}^{2}$ change in BMI and -3.76 to $-0.75 \mathrm{~cm}$ change in WC per 1-SD increase in these exposures. These observations may have important implications for the design of future studies aiming to reduce body weight or related adiposity outcomes, by focussing on key lifestyle behaviours that are associated with obesity.

Our findings corroborate, and provide new evidence, for associations between PA and obesity outcomes. A recent systematic review that have investigated the association between weight gain with physical activity have reported that physical activity levels that increase the total energy expenditure to $>1.7-1.8$ times the basal metabolic rate are needed to decrease obesity risk. ${ }^{21,22}$ This is in agreement with our finding where the magnitude of the effect of PA on obesity outcomes, especially for WC, was greater with higher intensity levels of physical activity (1 SD increase in light, moderate and vigorous intensity PA was associated with $-1.70,-1.96$ and $-2.63 \mathrm{~cm}$ lower WC, respectively). In addition, our results confirm previous findings that time spent in sedentary behaviours is associated with increased body weight and risk of obesity, independent of PA levels. ${ }^{23}$

Although unhealthy dietary patterns have been associated with obesity, there is inconsistency in the evidence about the role of specific food groups. ${ }^{24}$ Our study found that reported intakes of processed and red meat were associated with increased adiposity and obesity risk, independent of other confounding factors including total energy intake, total sugars, sedentary behaviour and physical activity. This is in agreement with previous studies showing that both red meat and processed meat, which have been linked to higher intake of total fat, saturated fat and energy dense food and lower intake of healthy foods such as vegetables, are positively associated with increased risk of obesity. ${ }^{25}$ 
Our findings shows a strong association between fat intake (total, mono and saturated fats) and obesity risk, which is in agreement with a recent review on the effect of reduced fat intake on body weight, which include data from 32 trials (approximately 54,000 participants) and from 25 cohort studies. ${ }^{26}$ This study reported that eating less fat (diet containing $<30 \%$ of TE from fat compared with usual diet) reduced mean BMI by $-0.5 \mathrm{~kg}(95 \% \mathrm{Cl}:-0.74$ to -0.26 $\mathrm{kg} / \mathrm{m}^{2}$ ), with greater weight loss resulting from greater fat reductions. ${ }^{26}$ These finding may have important clinical implications since reduced saturated fat intake is associated with a $17 \%$ reduction in the risk of cardiovascular disease. ${ }^{27}$ Our results are also in agreement with previous studies showing negative associations between intakes of dietary fibre, ${ }^{28}$ wholegrains ${ }^{29}$ and fruits and vegetable ${ }^{30}$ with obesity.

Interestingly, total sugar intake was inversely associated with BMI and WC independent of intakes of total energy and of other macronutrients including total fat, as has been reported in the UK Biobank study. ${ }^{31}$ However, intakes of sugar sweetened carbonated drinks were positively associated with BMI, WC and obesity risk. There was a similar positive association between intakes of sweets and pastries and obesity risk. This is in agreement with a systematic review which found that sugar sweetened carbonated drinks and sweets snacking were associated with increased obesity risk. ${ }^{32}$ The inverse association between sugar intake and obesity may seem counter-intuitive; however, this association may be explained by self-reporting bias, with previous studies suggesting that it may be easier for individuals to report intake of food items (i.e. fizzy drinks, chocolate, etc.) than total sugar intake. ${ }^{33}$ The UK's Scientific Advisory Committee on Nutrition concluded that there is a lack of high quality scientific evidence to draw conclusions on the impact of sugars intake on body weight in adults. ${ }^{34}$

Although we identified associations between adiposity outcomes and intakes of individual macronutrients or food groups, dietary behaviours may be better captured by using an overall estimation of dietary quality, as dietary patterns correlate more strongly with adiposity and the risk of obesity. ${ }^{35,36}$ Our results agree with previous prospective studies which have reported inverse associations between obesity and overall MD scores. ${ }^{35,37,38}$ Such inverse associations have also been reported in most, ${ }^{39-43}$ but not all, ${ }^{44}$ cross-sectional studies. However, our study have found that olive oil consumption, an essential component of the Mediterranean diet, was associated with higher adiposity levels whereas a lower vegetable oil intake was associated a lower risk for obesity. The HEI has been inversely associated with the likelihood of being overweight or obesity. ${ }^{45}$ 


\section{Strengths and limitations}

252 We have collected data from adults aged $18-79$ years resident in seven European countries. Just $44.8 \%$ of participants had a BMI $>25 \mathrm{~kg} / \mathrm{m}^{2}$ which is broadly similar to that of European adults. ${ }^{46}$ However, our recruitment strategy was not designed specifically to yield a sample that is necessarily representative of the European adult population, ${ }^{47}$ and so that findings with respect to the European population as a whole should be interpreted cautiously. Physical activity data were collected objectively using a triaxial accelerometer which is likely to provide a better estimation of the true relationship with obesity than use of self-report instruments. A potential limitation of the study is that the majority of our data were collected by self-report via the internet, which could have introduced recall bias and measurement error. ${ }^{48}$ Although, the precision self-reported anthropometric data collected via the internet is high ${ }^{49}$ we cannot rule out a potential dilution bias due under-reporting of BMI, especially by those who were obese. The current study used cross-sectional data, which cannot provide evidence of causal relationships between dietary patterns or other behavioural factors and obesity outcomes.

In conclusion, healthy diet scores such as MD and HEI as well as food groups, nutrients and physical activity related behaviours were robustly associated with BMI and WC in adults from seven European countries. Our results show that higher levels of PA and higher diet quality attenuate, while more time spent in sedentary behaviours and higher consumption of processed meat, red meat and fats accentuate associations with BMI and WC. These findings are relevant for public health and suggest that promotion of increased PA, reduced sedentary behaviours and improved overall quality of dietary patterns is a key strategy for addressing the existing obesity epidemic and associated disease burden.

\section{ACKNOWLEDGMENTS}

272 The Food4me randomized controlled trial was funded by the European Commission under the Food, Agriculture, [265494].

The authors declare no conflict of interest. 


\section{AUTHOR CONTRIBUTION}

280 Author responsibilities were as follows: CCM, KML, AA, JCM performed the statistical analysis and wrote the 281 manuscript. YM, IT, CAD, ERG, LB, JAL, JAM, WHS, HD, MG and JCM contributed to the research design. JCM was the

282 Food4Me Proof of Principle study leader. CCM, CFMM, HF, CBO, CW, ALM, RF, SNC, RSC, CPL, MG, MCW, ERG, LB 283 and JCM contributed to the developing the Standardized Operating Procedures for the study. CCM, SNC, RSC, CW, $284 \mathrm{CBO}, \mathrm{HF}, \mathrm{CFMM}, \mathrm{AM}, \mathrm{RF}, \mathrm{CPL}, \mathrm{MG}, \mathrm{IT}, \mathrm{MCW}$ and JCM conducted the intervention. CCM, CFMM and WHS contributed 285 to physical activity measurements.

286 
1. Health Effects of Overweight and Obesity in 195 Countries over 25 Years. New England Journal of Medicine 2017; 377(1): 13-27. doi: 10.1056/NEJMoa1614362

7. Celis-Morales C, Livingstone KM, Marsaux CFM, Macready AL, Fallaize R, O'Donovan CB et al. Effect of personalized nutrition on health-related behaviour change: evidence from the Food4me European randomized controlled trial. International Journal of Epidemiology 2016. doi: 10.1093/ije/dyw186

8. WHO. Obesity: preventing and managing the global epidemic. Report of a WHO consultation, 2000. Report no.: 0512-3054.

9. Celis-Morales C, Livingstone KM, Woolhead C, Forster H, O'Donovan CB, Macready AL et al. How reliable is internet-based self-reported identity, socio-demographic and obesity measures in European adults? Genes \& nutrition 2015; 10(5): 476-476. doi: 10.1007/s12263-015-0476-0

10. European Commission. European skills, competences, qualifications and occupations. In, 2015.

11. Marsaux CFM, Celis-Morales C, Hoonhout J, Claassen A, Goris A, Forster H et al. Objectively Measured Physical Activity in European Adults: Cross-Sectional Findings from the Food4Me Study. Plos One 2016; 11(3). doi: 10.1371/journal.pone.0150902 
12. Forster H FR, Gallagher C, O'Donovan CB, Woolhead C, Walsh MC, Macready AL, Lovegrove JA, Mathers JC, Gibney MJ, Brennan L, Gibney ER. Online Dietary Intake Estimation: The Food4Me Food Frequency Questionnaire. J. Med. Internet Res. 2014; 16(6): e150.

13. Fallaize R, Forster H, Macready AL, Walsh MC, Mathers JC, Brennan L et al. Online Dietary Intake Estimation: Reproducibility and Validity of the Food4Me Food Frequency Questionnaire Against a 4-Day Weighed Food Record. J. Med. Internet Res. 2014; 16(8): e190. doi: 10.2196/jmir.3355

14. Fallaize R, Forster H, Macready AL, Walsh MC, Mathers JC, Brennan L et al. Online Dietary Intake Estimation: Reproducibility and Validity of the Food4Me Food Frequency Questionnaire Against a 4-Day Weighed Food Record. Journal of Medical Internet Research 2014; 16(8). doi: 10.2196/jmir.3355

15. Forster H, Fallaize R, Gallagher C, O'Donovan CB, Woolhead C, Walsh MC et al. Online dietary intake estimation: the Food4Me food frequency questionnaire. Journal of Medical Internet Research 2014; 16(6): e150-e150. doi: 10.2196/jmir.3105

16. Food Standards Agency. McCance and Widdowson's The Composition of Foods, Sixth summary edition edn Royal Society of Chemistry: Cambridge, 2002.

17. Celis-Morales C, Livingstone KM, Marsaux CFM, Forster H, O'Donovan CB, Woolhead C et al. Design and baseline characteristics of the Food4Me study: a web-based randomised controlled trial of personalised nutrition in seven European countries. Genes Nutr 2015; 10(1): 450. doi: $10.1007 / \mathrm{s} 12263-014-0450-2$

18. Martínez-González MÁ, Corella D, Salas-Salvadó J, Ros E, Covas MI, Fiol M et al. Cohort Profile: Design and methods of the PREDIMED study. Int. J. Epidemiol. 2012; 41(2): 377-385. doi: 10.1093/ije/dyq250

19. Guenther PM, Kirkpatrick SI, Reedy J, Krebs-Smith SM, Buckman DW, Dodd KW et al. The Healthy Eating Index-2010 Is a Valid and Reliable Measure of Diet Quality According to the 2010 Dietary Guidelines for Americans. Journal of Nutrition 2014; 144(3): 399-407. doi: 10.3945/jn.113.183079

20. Livingstone KM, Celis-Morales C, Macready AL, Fallaize R, Forster H, Woolhead Cet al. Characteristics of European adults who dropped out from the Food4Me Internet-based personalised nutrition intervention. Public Health Nutrition 2016: 1-11. doi: $10.1017 / \mathrm{S} 1368980016002020$

21. Saris WHM, Blair SN, van Baak MA, Eaton SB, Davies PSW, Di Pietro L et al. How much physical activity is enough to prevent unhealthy weight gain? Outcome of the IASO 1st Stock Conference and consensus statement. Obesity reviews : an official journal of the International Association for the Study of Obesity 2003; 4(2): 101-114. doi: 10.1046/j.1467-789X.2003.00101.x 
22. Erlichman J, Kerbey AL, James WPT. Physical activity and its impact on health outcomes. Paper 2: Prevention of unhealthy weight gain and obesity by physical activity: an analysis of the evidence. Obesity reviews : an official journal of the International Association for the Study of Obesity 2002; 3(4): 273-287. doi: 10.1046/j.1467-789X.2002.00078.x

23. Thorp AA, Owen N, Neuhaus M, Dunstan DW. Sedentary Behaviors and Subsequent Health Outcomes in Adults A Systematic Review of Longitudinal Studies, 1996-2011. American Journal of Preventive Medicine 2011; 41(2): 207-215. doi: 10.1016/j.amepre.2011.05.004

24. Togo $\mathrm{P}$, Osler $\mathrm{M}$, Sorensen $\mathrm{T}$, Heitmann B. Food intake patterns and body mass index in observational studies. International Journal of Obesity 2001; 25(12): 1741-1751. doi: 10.1038/sj.ijo.0801819

25. Rouhani MH, Salehi-Abargouei A, Surkan PJ, Azadbakht L. Is there a relationship between red or processed meat intake and obesity? A systematic review and meta-analysis of observational studies. Obesity Reviews 2014; 15(9): 740-748. doi: 10.1111/obr.12172

26. Hooper L, Abdelhamid A, Bunn D, Brown T, Summerbell CD, Skeaff CM. Effects of total fat intake on body weight. Cochrane Database of Systematic Reviews 2015; (8). doi: 10.1002/14651858.CD011834

27. Hooper L, Martin N, Abdelhamid A, Davey Smith G. Reduction in saturated fat intake for cardiovascular disease. Cochrane Database of Systematic Reviews 2015; (6). doi: 10.1002/14651858.CD011737

28. Ludwig DS, Pereira MA, Kroenke CH, Hilner JE, Van Horn L, Slattery ML et al. Dietary fiber, weight gain, and cardiovascular disease risk factors in young adults. Jama-Journal of the American Medical Association 1999; 282(16): 1539-1546. doi: 10.1001/jama.282.16.1539

29. McKeown NM, Yoshida M, Shea MK, Jacques PF, Lichtenstein AH, Rogers G et al. Whole-Grain Intake and Cereal Fiber Are Associated with Lower Abdominal Adiposity in Older Adults. Journal of Nutrition 2009; 139(10): 1950-1955. doi: 10.3945/jn.108.103762

30. SchwingshackI L, Hoffmann G, Kalle-UhImann T, Arregui M, Buijsse B, Boeing H. Fruit and Vegetable Consumption and Changes in Anthropometric Variables in Adult Populations: A Systematic Review and Meta-Analysis of Prospective Cohort Studies. Plos One 2015; 10(10). doi: 10.1371/journal.pone.0140846

31. Anderson J, Celis-Morales C, Mackay D, Iliodromiti S, Lyall D, Sattar N et al. Adiposity among 132479 UK Biobank participants; contribution of sugar intake vs other macronutrients. Int J Epidemio/ 2016. doi: 10.1093/ije/dyw173 
32. Malik VS, Pan A, Willett WC, Hu FB. Sugar-sweetened beverages and weight gain in children and adults: a systematic review and meta-analysis. American Journal of Clinical Nutrition 2013; 98(4): 1084-1102. doi: 10.3945/ajcn.113.058362

33. Kuhnle GGC, Tasevska N, Lentjes MAH, Griffin JL, Sims MA, Richardson L et al. Association between sucrose intake and risk of overweight and obesity in a prospective sub-cohort of the European Prospective Investigation into Cancer in Norfolk (EPIC-Norfolk). Public Health Nutrition 2015; 18(15): 2815-2824. doi: 10.1017/s1368980015000300

34. Scientific Advisory Committee on Nutrition. Carbohydrates and Health. The Stationery Office: London, 2015.

35. Lassale C, Fezeu L, Andreeva VA, Hercberg S, Kengne AP, Czernichow S et al. Association between dietary scores and 13-year weight change and obesity risk in a French prospective cohort. International Journal of Obesity 2012; 36(11): 1455-1462. doi: 10.1038/ijo.2011.264

36. Mozaffarian D, Hao T, Rimm EB, Willett WC, Hu FB. Changes in Diet and Lifestyle and Long-Term Weight Gain in Women and Men. New England Journal of Medicine 2011; 364(25): 2392-2404.

37. Sanchez-Villegas A, Bes-Rastrollo M, Martinez-Gonzalez MA, Serra-Majem L. Adherence to a Mediterranean dietary pattern and weight gain in a follow-up study: the SUN cohort. International Journal of Obesity 2006; 30(2): 350-358. doi: 10.1038/sj.ijo.0803118

38. Romaguera D, Norat T, Vergnaud A-C, Mouw T, May AM, Agudo A et al. Mediterranean dietary patterns and prospective weight change in participants of the EPIC-PANACEA project. American Journal of Clinical Nutrition 2010; 92(4): 912-921. doi: 10.3945/ajcn.2010.29482

39. Schroder H, Marrugat J, Vila J, Covas MI, Elosua R. Adherence to the traditional Mediterranean diet is inversely associated with body mass index and obesity in a Spanish population. Journal of Nutrition 2004; 134(12): 3355-3361.

40. Panagiotakos DB, Chrysohoou C, Pitsavos C, Stefanadis C. Association between the prevalence of obesity and adherence to the Mediterranean diet: the ATTICA study. Nutrition 2006; 22(5): 449456. doi: 10.1016/j.nut.2005.11.004

41. Romaguera D, Norat T, Mouw T, May AM, Bamia C, Slimani N et al. Adherence to the Mediterranean Diet Is Associated with Lower Abdominal Adiposity in European Men and Women. Journal of Nutrition 2009; 139(9): 1728-1737. doi: 10.3945/jn.109.108902

42. Serra-Majem L, Roman B, Estruch R. Scientific evidence of interventions using the Mediterranean diet: A systematic review. Nutrition Reviews 2006; 64(2): S27-S47. doi: 10.1301/nr.2006.feb.S27S47 
43. Buckland G, Bach A, Serra-Majem L. Obesity and the Mediterranean diet: a systematic review of observational and intervention studies. Obesity Reviews 2008; 9(6): 582-593. doi: 10.1111/j.1467789X.2008.00503.x

44. Trichopoulou A, Naska A, Orfanos P, Trichopoulos D. Mediterranean diet in relation to body mass index and waist-to-hip ratio: the Greek European Prospective Investigation into Cancer and Nutrition Study. American Journal of Clinical Nutrition 2005; 82(5): 935-940.

45. Guo X, Warden BA, Paeratakul S, Bray GA. Healthy eating index and obesity. European Journal of Clinical Nutrition 2004; 58(12): 1580-1586. doi: 10.1038/sj.ejcn.1601989

46. OECD. Health at a Glance: Europe 2012: Paris, 2012.

47. Livingstone K, Celis-Morales C, Navas-Carretero S, San-Cristobal R, O'Donovan C, Forster H et al. Profile of European adults interested in internet-based personalised nutrition: the Food4Me study. Eur J Nutr 2015: 1-11. doi: 10.1007/s00394-015-0897-y

48. Cook C. Mode of administration bias. J. Man. Manip. Ther. 2010; 18(2): 61-63. doi: doi:10.1179/106698110X12640740712617

49. Pursey K, Burrows LT, Stanwell P, Collins EC. How Accurate is Web-Based Self-Reported Height, Weight, and Body Mass Index in Young Adults? J Med Internet Res 2014; 16(1): e4. doi: 10.2196/jmir.2909 
Figure 1. Odds ratios for overall and central obesity by socio-demographic and physical activity

483 Data presented as adjusted odds ratio and $95 \% \mathrm{Cl}$. Models were adjusted for age, sex, country and occupation. 484 Physical activity-related exposures were additionally adjusted for total energy intake and wearing time. Physical activity related variables are presented as tertiles. The lowest tertile (Least active) was used as the reference group, except for sedentary behaviour where the highest tertile was used as the reference category. Overweight or obesity was defined as $\mathrm{BMI} \geq 25.0 \mathrm{~kg} / \mathrm{m}^{2}$ and central obesity was defined as waist circumference $>88 \mathrm{~cm}$ for females and $>102 \mathrm{~cm}$ for males. PA: physical activity.

Figure 2. Odds ratios for overall and central obesity by tertile of nutrients intake

Data presented as adjusted odds ratio and $95 \% \mathrm{Cl}$. Models were adjusted for age, sex, country and occupation. Dietary fibre and salt were additionally adjusted for total energy intake. All exposures are presented as tertile. The highest tertile (highest intake) was used as reference group, except for dietary fibre, where the lowest tertile (lowest intake) was used as reference group. Overweight or obesity was defined as $\mathrm{BMI} \geq 25.0 \mathrm{~kg} / \mathrm{m}^{2}$ and central obesity was defined as waist circumference $>88 \mathrm{~cm}$ for females and $>102 \mathrm{~cm}$ for males.

Figure 3. Odds ratios for overall and central obesity by tertile of food groups and diet quality score

Data presented as adjusted odds ratio and $95 \% \mathrm{Cl}$. Models were adjusted for age, sex, country, occupation and total energy intake. All exposures are presented as tertiles. Overweight or obesity was defined as BMI $\geq 25.0 \mathrm{~kg} / \mathrm{m}^{2}$ and central obesity was defined as waist circumference $>88 \mathrm{~cm}$ for females and $>102 \mathrm{~cm}$ for males. 